\title{
Ingestion of a Moderately High Caffeine Dose Before Exercise Increases Postexercise Energy Expenditure
}

\author{
Valentín E. Fernández-Elías, Juan Del Coso, Nassim Hamouti, Juan F. Ortega, Gloria \\ Muñoz, Jesus Muñoz-Guerra, and Ricardo Mora-Rodríguez
}

\begin{abstract}
Caffeine is an ergogenic aid widely used before and during prolonged exercise. Due to its prolonged biological half-life caffeine effects could remain after exercise. We aimed to investigate the metabolic, respiratory, and cardiovascular postexercise responses to preexercise graded caffeine ingestion. Twelve aerobically trained subjects ( $\operatorname{mean} \mathrm{VO}_{2 \max }=54 \pm 7$ $\left.\mathrm{ml} \cdot \mathrm{min}^{-1} \cdot \mathrm{kg}^{-1}\right)$ cycled for 60 -min at $75 \% \mathrm{VO}_{2 \max }$ after ingesting placebo ( $0 \mathrm{mg}$ of caffeine per $\mathrm{kg}$ of body weight $)$ or 0.5 , $1.5,3.0$ and $4.5 \mathrm{mg} \cdot \mathrm{kg}^{-1}$ on five occasions. During the $3 \mathrm{hr}$ postexercise, heart rate, blood pressure, glucose, lactate, and fatty acids were analyzed. None of these variables were statistically affected by preexercise caffeine ingestion between 0.5 and $4.5 \mathrm{mg} \cdot \mathrm{kg}^{-1}$. However, ingestion of $4.5 \mathrm{mg} \cdot \mathrm{kg}^{-1}$ of caffeine raised postexercise energy expenditure $15 \%$ above placebo $(233 \pm 58$ vs. $202 \pm 49 \mathrm{kcal} / 3 \mathrm{hr} ; p<.05)$. Ventilation and tidal volume were elevated after the $4.5 \mathrm{mg} \cdot \mathrm{kg}^{-1} \mathrm{caffeine}$ dose above placebo $\left(9.2 \pm 2.5 \mathrm{~L} \cdot \mathrm{min}^{-1}\right.$ and $0.67 \pm 0.29 \mathrm{~L} \cdot$ breath $^{-1}$ vs. $7.8 \pm 1.5 \mathrm{~L} \cdot \mathrm{min}^{-1}$ and $0.56 \pm 0.20 \mathrm{~L} \cdot$ breath $^{-1}$, respectively; $p<.05)$. Ventilation correlated with tidal volume $(r=.45 ; p<.05)$ and energy expenditure $(r=.72 ; p<.05)$. In summary, preexercise ingestion of ergogenic caffeine doses do not alter postexercise cardiovascular responses. However, ingestion of $4.5 \mathrm{mg} \cdot \mathrm{kg}^{-1}$ of caffeine raises 3 -hr postexercise energy expenditure (i.e., $31 \mathrm{kcal}$ ) likely through increased energy cost of ventilation.
\end{abstract}

Keywords: metabolic rate, ventilation, heart rate

Caffeine (1, 3, 7 -trimethylxanthine) is the most used drug worldwide and it can be ingested from natural sources such as coffee, tea or chocolate, or included in cola-soft drinks and energy drinks. Because of the ergogenic properties of caffeine most exercise related research has focused on performance outcomes. However, due to its prolonged biological half-life (5-6 $\mathrm{hr}$ (Kamimori et al., 2002)) caffeine ingested to enhance exercise performance could result in metabolic and cardiorespiratory effects postexercise. For instance, a high dose of caffeine ingestion may lead to tachycardia (Cole et al., 1996), elevated blood pressure (Arciero et al., 1998), gastrointestinal problems, nervousness and affect sleep quality after exercise (Pallares et al., 2013). On the other hand, caffeine may improve substrate recovery (Battram et al., 2004; Pedersen et al., 2008) or could be

Fernández-Elías, Hamouti, Ortega, and Mora-Rodríguez are with the Exercise Physiology Laboratory, University of Castilla-La Mancha, Toledo, Spain. Coso is with the Exercise Physiology Laboratory, Camilo José Cela University, Madrid, Spain. Muñoz and MuñozGuerra are with the Spanish Anti-doping Agency, Doping Control Laboratory, Madrid, Spain. Address author correspondence to Ricardo Mora-Rodríguez at ricardo.mora@uclm.es used to increase postexercise energy expenditure and promote fat loss. Indeed, caffeine is in the main component in several over-the-counter preparations allegedly useful for weight management, although none scientifically proven (Hallas et al., 2008).

The ergogenic effect of caffeine on endurance has been shown when ingesting relatively low doses (1-3 mg - $\mathrm{kg}^{-1}$; Jenkins et al., 2008; Kovacs et al., 1998) and also after ingesting high doses (5-13 $\mathrm{mg} \cdot \mathrm{kg}^{-1}$; Pasman et al., 1995). However, Graham and Spriet (1995) found that the minimal caffeine dose that delays time to exhaustion when cycling at high intensity $\left(85 \% \mathrm{VO}_{2 \max }\right)$ was $3 \mathrm{mg}$. $\mathrm{kg}^{-1}$. Kovacs et al., (Kovacs et al., 1998) using a time trial endurance test found that caffeine doses from 2.1 to 4.5 $\mathrm{mg} \cdot \mathrm{kg}^{-1}$ had a significant ergogenic effect. In addition, resistance sports have been the target of investigations addressing caffeine effects (Astorino et al., 2007, 2011; Mora-Rodriguez et al., 2012; Pallares et al., 2013). We have recently found that caffeine doses from 3 to $9 \mathrm{mg}$. $\mathrm{kg}^{-1}$ have an ergogenic effect during resistance exercise (Pallares et al., 2013). In contrast to the abundant information during exercise, the postexercise effects of different doses of caffeine taken for ergogenic purposes are not well defined.

It has been shown that caffeine ingestion increases resting energy expenditure (REE) (Diepvens et al., 2007; 
Higgins \& Means, 1915; Phung et al., 2010; WesterterpPlantenga et al., 2006). However, despite the increase in REE, there is no convincing evidence that caffeine would promote or maintain weight loss in humans (Astrup et al., 1992; Pasman et al., 1997). To our knowledge, only two studies have focused on the dose-response effects of caffeine on REE (Astrup et al., 1990; Haldi et al., 1941). Haldi et al. (1941) found a dose-response effect of caffeine ingestion on REE, but the conclusions are based on data in two subjects. Astrup et al. (1990) showed that the highest and the lowest caffeine dose (400 and $100 \mathrm{mg}$ ) raised REE above placebo but not the intermediate dose (200 mg of caffeine). Hollands and coworkers (Hollands et al., 1981) supplied subjects with $1.5 \mathrm{mg} \cdot \mathrm{kg}^{-1}$ and found $15 \%$ elevations in REE during $2 \mathrm{hr}$ after its consumption. In contrast, Arciero et al. (1995) found an increase of $2 \%$ in REE after consuming $4.4 \mathrm{mg}$ of caffeine - $\mathrm{kg}^{-1}$ of body mass. Thus, the dose-response relationship between caffeine and REE is not clearly established.

The postexercise effects of caffeine ingestion on the cardiovascular system are also controversial. Studies at rest suggests that caffeine ingestion (i.e., $5 \mathrm{mg} \cdot \mathrm{kg}^{-1}$ ) rises blood pressure in the elderly population without altering heart rate (Arciero et al., 1998). To our knowledge, only Notarius et al. (2006) and Astorino et al. (2013) investigated the cardiovascular postexercise effects of caffeine ingestion. Notarius et al. (Notarius et al., 2006) intravenously infused $4 \mathrm{mg} \cdot \mathrm{kg}^{-1}$ of caffeine preexercise, and found that $10 \mathrm{~min}$ after exercise, arterial pressure, and heart rate were significantly higher than in the placebo trial. On the other hand, Astorino et al. (2013) provided 6 $\mathrm{mg} \cdot \mathrm{kg}^{-1}$ orally, preexercise, and did not observe any change in arterial pressure during the $70 \mathrm{~min}$ that followed exercise. Therefore, there are contradictory effects of caffeine on postexercise cardio-vascular responses and this warrants further investigation.

The purpose of this study was to determine if caffeine ingested preexercise in doses designed to enhance exercise performance, alters postexercise metabolic, cardiovascular and ventilatory responses. A second purpose was to determine for how long those responses will be altered. For that purpose, we monitored blood concentration of different substrates and metabolites, ventilation, heart rate, blood pressure and $\mathrm{VO}_{2}$ during the $3 \mathrm{hr}$ that followed $60 \mathrm{~min}$ of aerobic exercise. To comprehensively address the effects of caffeine we monitored all these variables after ingestion of different caffeine doses. We used doses that have a proven ergogenic endurance effect ( 3.0 and $4.5 \mathrm{mg} \cdot \mathrm{kg}^{-1}$ ) and doses that are habitually used by recreational athletes (0.5-1.0 mg $\cdot \mathrm{kg}^{-1}$ from drinking caffeinated colas and energy drinks). To our knowledge, this dose-response design of addressing postexercise caffeine effects is novel and may help to understand REE elevations after caffeine consumption.

\section{Methods}

\section{Subjects}

Twelve aerobically trained $\left(\sim 1 \mathrm{hr} \cdot\right.$ day $^{-1}, 4-7$ days week $^{-1}$ of cycling or running) healthy young subjects were recruited to participate in this study. They had a mean \pm $S D$ age of $27 \pm 8 \mathrm{yrs}$, body mass of $66 \pm 12 \mathrm{~kg}$, height of $171 \pm 10 \mathrm{~cm}$, and maximal oxygen uptake $\left(\mathrm{V}_{2 \max }\right)$ of 54 $\pm 6 \mathrm{ml} \cdot \mathrm{min}^{-1} \cdot \mathrm{kg}^{-1}$. The group included six women tested always in the luteal phase (Hackney et al., 1991). No participant had previous history of cardiopulmonary or metabolic diseases, or was taking medications during the study. Participants were no-smokers. A validated caffeine consumption questionnaire was used to document the subjects' self-reported habitual caffeine consumption (Shohet \& Landrum, 2001). The results revealed that all participants were light caffeine consumers $(<60 \mathrm{mg}$ per day, $\sim 1$ cup of coffee). Subjects were fully informed of any risks and discomforts associated with the experiments before giving their informed written consent to participate. The study was approved by the local Research Ethics Committee.

\section{Preliminary Testing}

Before the onset of the experiment participants underwent a physical examination including rest and exercise ECG (Cosmed T12, Italy). They performed an incremental cycling test in an electromagnetically braked cycle ergometer (Cardiotest 100, Seca, Germany) to determine their maximal aerobic capacity $\left(\mathrm{VO}_{2 \max }\right)$. After a $5 \mathrm{~min}$ warm-up at $100 \mathrm{~W}$, participants began cycling at $125 \mathrm{~W}$ with increments of $25 \mathrm{~W}$ each minute to volitional fatigue. Gas exchange data were collected using an automated breath by breath system (Quark b2, Cosmed, Italy) and averaged every 15 s. Maximal oxygen uptake (i.e., $\mathrm{VO}_{2 \max }$ ) was defined as the highest plateau in oxygen consumption (two successive maximal readings within $0.15 \mathrm{~L} \cdot \min ^{-1}$ ) that occurred despite increases in workload. Data resulting from this test were used to set the exercise workload of each participant during the experimental trials.

\section{Experimental Design.}

A double-blind, placebo-controlled experimental design was used, with all subjects serving as their own controls. All participants were tested on five different occasions, separated by at least 3 days to allow caffeine washout. In each occasion, participants arrived to the laboratory in the early morning (i.e., before 8 a.m.) and received either 0 (placebo) $0.5,1.5,3.0$, or $4.5 \mathrm{mg}$ of caffeine per $\mathrm{kg}$ of body weight, $1 \mathrm{~h}$ before exercising for $60 \mathrm{~min}$ at $75 \%$ of their $\mathrm{VO}_{2 \max }$. These caffeine doses were chosen because they are habitual caffeine doses consumed by recreational, amateur and professional sportsmen (Froiland et al., 2004; Kristiansen et al., 2005; Magkos \& Kavouras, 2005). Environmental conditions remained thermoneutral $\left(22^{\circ} \mathrm{C}\right.$ and $40 \%$ relative humidity) during the whole experiment. After exercise, participants rested supine for $180 \mathrm{~min}$ 
while a blood sample was taken and heart rate (HR), blood pressure (BP), and ventilator parameters were monitored, at 60-min intervals. Caffeine (Durvitan, Seid, Spain) was provided in capsules filled with the corresponding dose normalized by body weight. In the trial without caffeine ingestion (i.e., $0 \mathrm{mg} \cdot \mathrm{kg}^{-1}$ ), subjects ingested the same number of capsules with the same appearance, but filled with $1 \mathrm{~g}$ of dextrose. An alphanumeric code was assigned to each trial to prevent subjects and investigators of knowing the caffeine dose tested. This code was unveiled after the analysis of the variables.

\section{Experimental Protocol}

Participants were asked to refrain from ingesting any caffeine source (i.e., coffee, tea, cola drinks, and chocolate) $48 \mathrm{hr}$ before the experimental trial. In addition, subjects were asked to refrain from performing intense exercise during the $24 \mathrm{hr}$ before and to replicate the same meal $3 \mathrm{hr}$ before arriving to the laboratory. Trials took place approximately at the same time of day to avoid an influence of circadian rhythm on the cardiovascular or metabolic variables (Bessot et al., 2007) and under the same environmental conditions (room temperature; i.e., $\sim 22{ }^{\circ} \mathrm{C}$ ). Upon arrival to the laboratory subjects lied down on a stretcher during $20 \mathrm{~min}$. Then a $22-\mathrm{G}$ catheter (Teflon; BD Insyte, Becton Dickinson, Spain) was inserted into an antecubital vein. The catheter was frequently flushed with $3-4 \mathrm{ml}$ of $0.9 \%$ sterile saline to ensure patency. After that, the caffeine dose or placebo assigned for the trial was ingested and participants rested for $60 \mathrm{~min}$. Following, subjects cycled continuously for $60 \mathrm{~min}$ interspersed with measurements of maximal cycling power using three 4-s all-out sprints (Coso \& Mora-Rodríguez, 2006). Data concerning the exercise portion of the protocol have been presented and discussed elsewhere (Del Coso et al., 2010). The exercise intensity $\left(75 \% \mathrm{VO}_{2 \max }\right)$ and oxygen consumption were not different among trials (mean of $2722 \pm 694 \mathrm{ml} \cdot \mathrm{kg}^{-1} \cdot \mathrm{min}^{-1}$ ). Once the exercise protocol was concluded, participants ate a light snack (284 kcal; $36 \mathrm{~g}$ of carbohydrates, $3.3 \mathrm{~g}$ of protein and $14 \mathrm{~g}$ of fat) and drank water to fully recover the amount of fluid lost during exercise $(? 0.5 \mathrm{~L})$. Thereafter, participants rested for $180 \mathrm{~min}$ on a stretcher, while $\mathrm{HR}, \mathrm{BP}$, and ventilator parameters were monitored during $4 \mathrm{~min}$ periods at the end of each hour. Blood samples were taken just before the 4 min measurement battery.

\section{Heart Rate and Blood Pressure}

Heart rate (HR) was measured using a heart rate monitor (RS 400, Polar, Finland). Systolic (SBP) and diastolic blood pressure (DBP) were measured in the right arm, in triplicate, using an automated blood pressure monitor (Tango, Suntech Med. Instruments, North Carolina, USA). Mean arterial pressure (MAP) was calculated as [(2 $\times \mathrm{DBP})+\mathrm{SBP}] / 3$.

\section{Ventilatory Parameters and Substrate Oxidation}

Oxygen consumption $\left(\mathrm{VO}_{2}\right)$ carbon dioxide production $\left(\mathrm{CO}_{2}\right)$, ventilation $\left(\mathrm{V}_{\mathrm{E}}\right)$ tidal volume $\left(\mathrm{V}_{\mathrm{T}}\right)$ and respiratory frequency $\left(\mathrm{R}_{\mathrm{F}}\right)$ were assessed using a computerized opencircuit spirometry (Quark b2, Cosmed, Italy). Data were collected during the last 4 min of each hour during the 3 $\mathrm{hr}$ recovery period. Energy Expenditure (EE) and substrate oxidation were calculated based on Brouwer formulae (Brouwer, 1957):

$$
\begin{gathered}
\mathrm{EE}\left(\mathrm{Kcal} \cdot \mathrm{min}^{-1}\right)=\left[\left(3.869 \times \mathrm{VO}_{2}\right)+\left(1.195 \times \mathrm{VCO}_{2}\right)\right] \\
\text { Fat oxidation }\left(\mathrm{g} \cdot \mathrm{min}^{-1}\right)=\left(1.67 \times \mathrm{VO}_{2}\right)-\left(1.67 \times \mathrm{VCO}_{2}\right) \\
\text { Carbohydrate oxidation }\left(\mathrm{g} \cdot \mathrm{min}^{-1}\right)=\left(4.55 \times \mathrm{VCO}_{2}\right)- \\
\left(3.21 \times \mathrm{VO}_{2}\right)
\end{gathered}
$$

with $\mathrm{VO}_{2}$ and $\mathrm{VCO}_{2}$ expressed in $\mathrm{L} \cdot \min ^{-1}$.

\section{Blood Variables}

Blood samples $(5 \mathrm{~mL})$ were taken at the end of each hour during the 3-hr postexercise period, right before collection of the other variables. A portion of the blood was allowed to clot in serum tubes ( $\mathrm{Z}$ Serum Sep Clot Activator Vacuette, Greiner Bio-One GmbH, Austria) and the remaining blood was mixed with ethylenediaminetetraacetic acid in polyethylene tubes and then spun at $2000 \times g$ for $10 \mathrm{~min}$ in a refrigerated $\left(4^{\circ} \mathrm{C}\right)$ centrifuge (MPW-350R, Med. Instruments, Poland). The plasma and serum portions of the blood were stored at -80 ${ }^{\circ} \mathrm{C}$ for future analysis. Plasma caffeine levels were analyzed using an Agilent Technologies HPLC 1200 system (Santa Clara, CA) coupled to a triple quadrupoleion trap mass spectrometer (MS; API 4000, QTRAP, AB SCIEX, Framingham, MA US). Blood serum samples were analyzed in duplicate for glucose $\left([\mathrm{Glu}]_{\text {serum }}\right)$ using an enzymatic glucose oxidase assay (Enzymatic Glucose Reagent, Thermoscientific, USA). Lactate concentration ([Lac $\left.]_{\text {serum }}\right)$ using an end-point reaction that involved lactate dehydrogenase and detection of NADH (Hohorst, 1965), and free fatty acids (FFA) using an enzymatic colorimetric method (WAKO Chemical Germany). All the measurements were performed using a multichannel spectrometer plate reader (Versamax, Molecular Devices, USA).

\section{Statistical Analysis.}

Data were analyzed using a two-way ANOVA (caffeine dose $\times$ time) with repeated measures. After a significant $F$ test (Geisser-Greenhouse correction for the assumption of sphericity), differences between means were identified by using Tukey's HSD post hoc procedure. The Pearson's correlation coefficient was used to establish relationship between variables. The significance level was set at $p<$ .05 . The data were analyzed using the software package SPSS v.19.0. The results presented are means $\pm S D$ unless otherwise is indicated. 


\section{Results}

Postexercise responses to caffeine ingestion were not different between our men and women and thus data have been pooled and analyzed as a group. Caffeine plasma levels (Table 1) were elevated in a dose-response pattern after exercise and remained at that level during the $3-\mathrm{hr}$ postexercise period. Total REE of the $3-\mathrm{hr}$ postexercise period rose $15 \%$ above placebo with the ingestion of 4.5 $\mathrm{mg} \cdot \mathrm{kg}^{-1}$ of caffeine $(233 \pm 58$ vs. $202 \pm 49 \mathrm{kcal} ; p<.05$; Figure 1). However, this increase in caloric expenditure did not produce a difference in substrate utilization and the percent of fat or carbohydrates oxidized remained similar among trials (Table 2). $\mathrm{V}_{\mathrm{E}}$ (Figure 1) and $\mathrm{V}_{\mathrm{T}}$ (Table 2) were also increased when ingesting $4.5 \mathrm{mg} \cdot \mathrm{kg}^{-1}$ of caffeine compared with placebo $\left(9.2 \pm 2.7 \mathrm{~L} \cdot \mathrm{min}^{-1}\right.$ and $0.67 \pm 0.29 \mathrm{~L} \cdot$ breaths $^{-1}$ vs. $7.8 \pm 1.5 \mathrm{~L} \cdot \mathrm{min}^{-1}$ and $0.56 \pm$ $0.2 \mathrm{~L} \cdot$ breaths $^{-1}$ respectively, $p<.05$ ), although there were no differences in $\mathrm{R}_{\mathrm{F}}$ (Table 2). The increases in ventilation correlated with the increases in REE and $\mathrm{V}_{\mathrm{T}}$ when all trials were considered $(r=.72$ and 0.45 , respectively; $p<$ .05 ; Figure 2).

HR and MAP during the 3-hr postexercise period were not different among trials (Table 3). Neither, $[\mathrm{Glu}]_{\text {serum, }}[\mathrm{Lac}]_{\text {serum }}$ or FFA showed significant differences among trials during the $3-\mathrm{hr}$ postexercise period (Table 3 ).

\section{Discussion}

It is a common practice to ingest caffeine before exercise to benefit from its ergogenic effect. Caffeine effects persist after exercise mostly if exercise is short duration ( $\leq$ $60 \mathrm{~min})$ due to its prolonged biological half-life (Kamimori et al., 2002). While there is abundant information on the cardiovascular and metabolic consequences of caffeine ingestion at rest, information is scarce when caffeine ingestion is followed by exercise. We currently investigated the metabolic and cardiorespiratory postexercise response to caffeine ingestion before exercise. We selected a range of caffeine doses from $0.5 \mathrm{mg} \cdot \mathrm{kg}^{-1}$ of body mass to $4.5 \mathrm{mg} \cdot \mathrm{kg}^{-1}$ of body mass, which include the more common doses used in recreational and competitive sports (Froiland et al., 2004; Kristiansen et al., 2005; Magkos \& Kavouras, 2005). The main findings of this study were: $a$ ) the consumption of $4.5 \mathrm{mg} \cdot \mathrm{kg}^{-1}$ of body mass of caffeine, before $60 \mathrm{~min}$ of intense cycling rose significantly (i.e., $15 \%$ ) resting energy expenditure (REE) during 3-hr postexercise; $b$ ) the higher REE was associated with higher ventilation $\left(\mathrm{V}_{\mathrm{E}}\right)$ and tidal volume. While heart rate, mean arterial pressure, and substrate utilization were not affected by caffeine, REE and $\mathrm{V}_{\mathrm{E}}$ appeared to increase in a dose-dependent manner.

It is well accepted that caffeine has a thermogenic effect at rest (Acheson et al., 1980; Ahrens et al., 2007; Phung et al., 2010; Westerterp-Plantenga et al., 2006). Nevertheless, information about the effects of preexercise caffeine ingestion on postexercise energy expenditure is scarce. To the best of our knowledge, only three studies have investigated the postexercise thermogenic effects of preexercise ingestion of caffeine. Chad and Quigley (Chad \& Quigley, 1989) observed an increased energy expenditure (i.e., 8\%), fat oxidation and blood FFA during the $1 \mathrm{hr}$ postexercise $(90 \mathrm{~min}$ of treadmill exercise at $55 \%$ $\mathrm{VO}_{2 \max }$ ) that followed preexercise caffeine ingestion (5 $\mathrm{mg} \cdot \mathrm{kg}^{-1}$ of body mass). Likewise, Donelly and McNaughton's work (Donelly \& McNaughton, 1992) shown increased REE ( $8 \%$ ) with the preexercise ingestion of $5 \mathrm{mg} \cdot \mathrm{kg}^{-1}$ of body mass $1 \mathrm{hr}$ after cycling $90 \mathrm{~min}$ at $55 \% \mathrm{VO}_{2 \max }$. We also report elevations in REE with the ingestion of our highest caffeine dose (i.e., $4.5 \mathrm{mg} \cdot \mathrm{kg}^{-1}$ of body mass). However, our subjects' FFA levels were not significantly elevated and neither their fat oxidation. This could be due to the effect of the snack provided after exercise. Likely the insulin response to the ingested carbohydrate blunted lipolysis and therefore fat oxidation (Horowitz et al., 1999).

Astorino's group (Astorino et al., 2011) recently reported that a dose of $6 \mathrm{mg} \cdot \mathrm{kg}^{-1}$ of caffeine, ingested preexercise, increased postexercise REE also by $15 \%$ when measured 75 min after a bout of resistance exercise. In our data REE was also elevated by $15 \%$ for three hours after continuous exercise. Thus it appears that exercise mode (endurance vs. resistance) does not alter the postexercise elevations in REE. Unfortunately, Astorino et al. did not explore other variables associated with the increase in REE. Thus, it is unknown if ventilation was also associated with the increased REE after caffeine ingestion and resistance exercise.

The association found between the increase in postexercise REE and $V_{E}$ suggests that the extra cost of breathing was behind the increased REE. An elevation in $\mathrm{V}_{\mathrm{E}}$ after caffeine ingestion has been previously reported by other investigators during both, rest (D'Urzo et al., 1990) and during exercise (Bell et al., 1999; D’Urzo et al., 1990). D'Urzo et al. (1990) measured the ventilatory response at rest under progressive hyperoxic hypercapnia and isocapnic hypoxia to produce higher ventilation response. In that study it was found that after the ingestion of $8.6 \mathrm{mg} \cdot \mathrm{kg}^{-1}$ of body mass of caffeine $V_{E}$ increased above the control trial. As in the current study, they observed that the higher $\mathrm{V}_{\mathrm{E}}$ at rest $\left(7.4-10.5 \mathrm{~L} \cdot \mathrm{min}^{-1}\right)$ was caused by a higher $\mathrm{V}_{\mathrm{T}}\left(0.74-0.94 \mathrm{~L} \cdot\right.$ breaths $\left.^{-1}\right)$, with little role for respiratory frequency $\left(\mathrm{R}_{\mathrm{F}}\right)$. At rest, in a supine position, expiration is passive and inspiratory muscles demand most of the energy for breathing. A more forceful contraction of the inspiratory muscles (i.e., diaphragm, intercostals, and sternocleidomastoids) may results in an elevated cost of breathing (West, 2012).

D'Urzo and collegues (1990) discussed that the ventilatory changes induced by caffeine ingestion may be associated to either, a bronchodilator effect or a stimulant effect on the respiratory muscles. However, a bronchodilator effect does not seem to be associated with caffeine ingestion. Powers et al. (1986) found no differences in forced vital capacity and forced expired volume after a dose of $7 \mathrm{mg} \cdot \mathrm{kg}^{-1}$ of caffeine ingestion. In turn, it has also been shown that caffeine supplied to 
infants enhanced their ventilaroty muscle strength (Kassim et al., 2009). It is then possible that caffeine may enhance inspiratory muscle recruitment by altering the medulla oblongata signals to recruit more inspiratory muscle. Alternatively caffeine may directly stimulate force generation in each inspiration raising $V_{T}$ through a local muscle effect as it has been speculated to take place in skeletal muscle (Mora-Rodriguez et al., 2012; Tarnopolsky \& Cupido, 2000).

As previously shown by Graham and Spriet (1995), caffeine ingestion has a dose-response effect on plasma catecholamines. Although the authors dispel the concept that caffeine ergogenic effect is meditated by increased plasma epinephrine, the postexercise metabolic and ventilator effects of caffeine-induced elevations in plasma catecholamines are, to our knowledge, unclear. Epinephrine increases muscle contraction force and carbohydrate oxidation which could have mediated the increased ventilatory response and energy expenditure presently found after the highest caffeine dose $(4.5 \mathrm{mg}$. $\mathrm{kg}^{-1}$ ). Thus, not having data on plasma catecholamines is a limitation of this study that is worth to mention.

In summary, an oral dose of $4.5 \mathrm{mg} \cdot \mathrm{kg}^{-1}$ of caffeine per body mass is required to affect postexercise metabolism, raising resting energy expenditure by $15 \%$. This increase seemed to be mediated by higher ventilation through an elevated tidal volume. In contrast, blood glucose $_{\overline{\mathbf{2}}}$ free fatty acids, fat, and carbohydrate oxidation were not significantly affected by preexercise caffeine ingestion. Preexercise caffeine ingestion ranging from 0.5 to $4.5 \mathrm{mg} \cdot \mathrm{kg}^{-1}$ of body mass did not have a clear cardiovascular postexercise effects with no changes on blood pressure or heart rate in our young-fit subjects.

\section{Novelty Statement}

Caffeine ingested preexercise as an ergogenic aid has metabolic consequences during the $3 \mathrm{hr}$ postexercise that have not been previously considered. A caffeine dose of $4.5 \mathrm{mg} \cdot \mathrm{kg}^{-1}$ of body mass raises postexercise resting energy expenditure by $15 \%$ in association with increased ventilation and tidal volume. More importantly, this increase in energy expenditure does not take place with lower caffeine doses (i.e., 1.5 , and $3 \mathrm{mg} \cdot \mathrm{kg}^{-1}$ ) that nonetheless could also result in ergogenic effects.

\section{Practical Application}

The use of caffeine before exercise in doses of $4.5 \mathrm{mg} \cdot \mathrm{kg}^{-}$ 1 of body mass or higher raises postexercise energy expenditure without any adverse cardiovascular effect. However, the magnitude of the increase in energy expenditure (31 kcals) although statistically significant, is small and the consequences for sport nutrition or body weight regulation remains to be determined.

\section{Acknowledgments}

The study was designed by VEF-E, JC, NH, JFO and RM-R; data were collected and analyzed by VEF-E, JC, NH, JFO, and RM-R; data interpretation and manuscript preparation were undertaken by VEF-E and RM-R. GM and JMG run the biochemical analysis of caffeine in blood samples. All authors approved the final version of the paper. The authors wish to thank the participants for their invaluable contribution to the study. This study was supported by a grant from the Junta de Comunidades de CastillaLa Mancha (PEII10-0215-3058). Valentín E. Fernández-Elías was supported by a predoctoral fellowship from the Junta de Comunidades de Castilla- La Mancha. The authors of this study declare that they have no financial, professional, or other personal interest of any nature in any product, service and/or company that could be construed as influencing the position presented in this manuscript.

\section{References}

Acheson, K.J., Zahorska-Markiewicz, B., Pittet, P., Anantharaman, K., \& Jéquier, E. (1980). Caffeine and coffee: their influence on metabolic rate and substrate utilization in normal weight and obese individuals. The American Journal of Clinical Nutrition, 33(5), 989-997. PubMed

Ahrens, J.N., Crixell, S.H., Lloyd, L.K., \& Walker, J.L. (2007). The physiological effects of caffeine in women during treadmill walking. Journal of Strength and Conditioning Research, 21(1), 164$168 . \quad \underline{\text { PubMed }} \quad \underline{\text { doi: } 10.1519 / 00124278-}$ 200702000-00029

Arciero, P.J., Gardner, A.W., Benowitz, N.L., \& Poehlman, E.T. (1998). Relationship of blood pressure, heart rate and behavioral mood state to norepinephrine kinetics in younger and older men following caffeine ingestion. European Journal of Clinical Nutrition, 52(11), 805-812. PubMed doi:10.1038/sj.ejcn.1600651

Arciero, P.J., Gardner, A.W., Calles-Escandon, J., Benowitz, N.L., \& Poehlman, E.T. (1995). Effects of caffeine ingestion on NE kinetics, fat oxidation, and energy expenditure in younger and older men. The American Journal of Physiology, 268(6 Pt 1), E1192-E1198. PubMed

Astorino, T.A., Rohmann, R., Firth, K., \& Kelly, S. (2007). Caffeine-induced changes in cardiovascular function during resistance training. International Journal of Sport Nutrition and Exercise Metabolism, 17(5), 468-477. PubMed

Astorino, T.A., Martin, B.J., Schachtsiek, L., \& Wong, K. (2013). Caffeine ingestion and intense resistance training minimize postexercise hypotension in normotensive and prehypertensive men. Research in Sports Medicine, 21(1), 52-65. PubMed

Astorino, T. A., Martin, B. J., Wong, K., \& Schachtsiek, L. (2011). Effect of acute caffeine ingestion on EPOC after intense resistance training. $J$ Sports Med Phys Fitness, 51(1), 11-17. doi: R40113044 [pii]

Astrup, A., Breum, L., Toubro, S., Hein, P., \& Quaade, F. (1992). The effect and safety of an ephedrine/caffeine compound compared to ephedrine, caffeine and placebo in obese subjects on an energy restricted diet. A double 
blind trial. International Journal of Obesity and Related Metabolic Disorders, 16(4), 269-277. PubMed

Astrup, A., Toubro, S., Cannon, S., Hein, P., Breum, L., \& Madsen, J. (1990). Caffeine: a doubleblind, placebo-controlled study of its thermogenic, metabolic, and cardiovascular effects in healthy volunteers. The American Journal of Clinical Nutrition, 51(5), 759-767. PubMed

Battram, D. S., Shearer, J., Robinson, D., \& Graham, T. E. (2004). Caffeine ingestion does not impede the resynthesis of proglycogen and macroglycogen after prolonged exercise and carbohydrate supplementation in humans. Journal of Applied Physiology (1985), 96(3), 943-950.

doi:

10.1152/japplphysiol.00745.2003

Bell, C., Kowalchuk, J.M., Paterson, D.H., Scheuermann, B.W., \& Cunningham, D.A. (1999). The effects of caffeine on the kinetics of $\mathrm{O} 2$ uptake, $\mathrm{CO} 2$ production and expiratory ventilation in humans during the on-transient of moderate and heavy intensity exercise. Experimental Physiology, 84(4), 761-774. PubMed doi:10.1111/j.1469-445X.1999.01863.X

Bessot, N., Moussay, S., Clarys, J.P., Gauthier, A., Sesboüé, B., \& Davenne, D. (2007). The influence of circadian rhythm on muscle activity and efficient force production during cycling at different pedal rates. Journal of Electromyography and Kinesiology, 17(2), 176183. PubMed doi:10.1016/j.jelekin.2006.01.007

Brouwer, E. (1957). On simple formulae for calculating the heat expenditure and the quantities of carbohydrate and fat oxidized in metabolism of men and animals, from gaseous exchange (Oxygen intake and carbonic acid output) and urine-N. Acta Physiologica et Pharmacologica Neerlandica, 6(1), 795-802. PubMed

Cole, K.J., Costill, D.L., Starling, R.D., Goodpaster, B.H., Trappe, S.W., \& Fink, W.J. (1996). Effect of caffeine ingestion on perception of effort and subsequent work production. International Journal of Sport Nutrition, 6(1), 14-23. PubMed

Coso, J.D., \& Mora-Rodríguez, R. (2006). Validity of cycling peak power as measured by a shortsprint test versus the Wingate anaerobic test. Applied Physiology, Nutrition, and Metabolism, 31(3), 186-189. PubMed doi:10.1139/h05-026

Chad, K., \& Quigley, B. (1989). The effects of substrate utilization, manipulated by caffeine, on post-exercise oxygen consumption in untrained female subjects. European Journal of Applied Physiology and Occupational Physiology, 59(12), 48-54. PubMed doi:10.1007/BF02396579

D’Urzo, A.D., Jhirad, R., Jenne, H., Avendano, M.A., Rubinstein, I., \& D'Costa, M. (1990). Effect of caffeine on ventilatory responses to hypercapnia, hypoxia, and exercise in humans. Journal of Applied Physiology (Bethesda, Md.), 68(1), 322-328. PubMed
Del Coso, J., Hamouti, N., Fernández-Elias, V.E., Ortega, J.F., Muñoz-Guerra, J., \& MoraRodriguez, R. (2010). Dose-response benefits of caffeine ingestion on sprint performance during high-intensity exercise. Medicine and Science in Sports and Exercise, 42(5, Supplement) S78.

Diepvens, K., Westerterp, K. R., \& WesterterpPlantenga, M. S. (2007). Obesity and thermogenesis related to the consumption of caffeine, ephedrine, capsaicin, and green tea. American Journal of Physiology-Regulatory, Integrative and Comparative Physiology, 292(1), R77-85. doi: 00832.2005

Donelly, K., \& McNaughton, L. (1992). The effects of two levels of caffeine ingestion on excess postexercise oxygen consumption in untrained women. European Journal of Applied Physiology and Occupational Physiology, 65(5), 459-463. PubMed doi:10.1007/BF00243514

Froiland, K., Koszewski, W., Hingst, J., \& Kopecky, L. (2004). Nutritional supplement use among college athletes and their sources of information. International Journal of Sport Nutrition and Exercise Metabolism, 14(1), 104-120. PubMed

Graham, T.E., \& Spriet, L.L. (1995). Metabolic, catecholamine, and exercise performance responses to various doses of caffeine. Journal of Applied Physiology (Bethesda, Md.), 78(3), 867-874. PubMed

Hackney, A.C., Curley, C.S., \& Nicklas, B.J. (1991). Physiological responses to submaximal exercise at the mid-follicular, ovulatory and mid-luteal phases of the menstrual cycle. Scandinavian Journal of Medicine \& Science in Sports, 1(2), 94-98. doi:10.1111/j.1600-0838.1991.tb00277.x

Haldi, J., Bachmann, G., Ensor, C., \& Wynn, W. (1941). The effect of various amounts of caffeine on the gaseous exchange and the respiratory quotient in man. The Journal of Nutrition, 21(3), 307-320.

Hallas, J., Bjerrum, L., Stovring, H., \& Andersen, M. (2008). Use of a prescribed ephedrine/caffeine combination and the risk of serious cardiovascular events: a registry-based case-crossover study. American Journal of Epidemioogyl, 168(8), 966-973.

Higgins, H.L., \& Means, H.J. (1915). The effect of certain drugs on the respiration and gaseous metabolism in normal human subjects. The Journal of Pharmacology and Experimental Therapeutics, 7(1), 1-30.

Hohorst, H.J. (1965). Determination of L-lactate with $L D H$ and $D P H$. New York: Academic Press.

Hollands, M.A., Arch, J.R., \& Cawthorne, M.A. (1981). A simple apparatus for comparative measurements of energy expenditure in human subjects: the thermic effect of caffeine. The American Journal of Clinical Nutrition, 34(10), 2291-2294. PubMed

Horowitz, J.F., Mora-Rodriguez, R., Byerley, L.O., \& Coyle, E.F. (1999). Substrate metabolism when subjects are fed carbohydrate during exercise. 
The American Journal of Physiology, 276(5 Pt 1), E828-E835. PubMed

Jenkins, N.T., Trilk, J.L., Singhal, A., O’Connor, P.J., \& Cureton, K.J. (2008). Ergogenic Effects of Low Doses of Caffeine on Cycling Performance. International Journal of Sport Nutrition and Exercise Metabolism, 18, 328-342. PubMed

Kamimori, G.H., Karyekar, C., Otterstetter, R., Cox, D., Balkin, T., \& Belenky, G. (2002). The rate of absorption and relative bioavailability of caffeine administered in chewing gum versus capsules to normal healthy volunteers. International Journal of Pharmaceutics, 234(12), 159-167. PubMed doi:10.1016/S03785173(01)00958-9

Kassim, Z., Greenough, A., \& Rafferty, G.F. (2009). Effect of caffeine on respiratory muscle strength and lung function in prematurely born, ventilated infants. European Journal of Pediatrics, 168(12), 1491-1495. PubMed doi:10.1007/s00431-009-0961-9

Kovacs, E.M., Stegen, J., \& Brouns, F. (1998). Effect of caffeinated drinks on substrate metabolism, caffeine excretion, and performance. Journal of Applied Physiology (Bethesda, Md.), 85(2), 709715. PubMed

Kristiansen, M., Levy-Milne, R., Barr, S., \& Flint, A. (2005). Dietary supplement use by varsity athletes at a Canadian university. International Journal of Sport Nutrition and Exercise Metabolism, 15(2), 195-210. PubMed

Magkos, F., \& Kavouras, S.A. (2005). Caffeine use in sports, pharmacokinetics in man, and cellular mechanisms of action. Critical Reviews in Food Science and Nutrition, 45(7-8), 535-562. PubMed doi:10.1080/1040-830491379245

Mora-Rodriguez, R., Garcia Pallares, J., LopezSamanes, A., Ortega, J.F., \& Fernandez-Elias, V.E. (2012). Caffeine ingestion reverses the circadian rhythm effects on neuromuscular performance in highly resistance-trained men. PLoS ONE, 7(4), e33807. PubMed doi:10.1371/journal.pone.0033807

Notarius, C.F., Morris, B.L., \& Floras, J.S. (2006). Caffeine attenuates early post-exercise hypotension in middle-aged subjects. American Journal of Hypertension, 19(2), 184-188. PubMed doi:10.1016/j.amjhyper.2005.07.022

Pallares, J.G., Fernandez-Elias, V.E., Ortega, J.F., Munoz, G., Munoz-Guerra, J., \& MoraRodriguez, R. (2013). Neuromuscular responses to incremental caffeine doses: performance and side effects. Medicine and Science in Sports and Exercise, 45(11), 2184-2192. PubMed doi:10.1249/MSS.0b013e31829a6672

Pasman, W.J., van Baak, M.A., Jeukendrup, A.E., \& de Haan, A. (1995). The effect of different dosages of caffeine on endurance performance time. International Journal of Sports Medicine, 16(4), 225-230. PubMed doi:10.1055/s-2007$\underline{972996}$
Pasman, W.J., Westerterp-Plantenga, M.S., \& Saris, W.H. (1997). The effectiveness of long-term supplementation of carbohydrate, chromium, fibre and caffeine on weight maintenance. International Journal of Obesity and Related Metabolic Disorders, 21(12), 1143-1151. PubMed doi:10.1038/sj.ijo.0800528

Pedersen, D. J., Lessard, S. J., Coffey, V. G., Churchley, E. G., Wootton, A. M., Ng, T. (2008). High rates of muscle glycogen resynthesis after exhaustive exercise when carbohydrate is coingested with caffeine. J Appl Physiol (1985), 105(1), 7-13.

Phung, O.J., Baker, W.L., Matthews, L.J., Lanosa, M., Thorne, A., \& Coleman, C.I. (2010). Effect of green tea catechins with or without caffeine on anthropometric measures: a systematic review and meta-analysis. The American Journal of Clinical Nutrition, 91(1), 73-81. PubMed doi:10.3945/ajen.2009.28157

Powers, S.K., Dodd, S., Woodyard, J., \& Mangum, M. (1986). Caffeine alters ventilatory and gas exchange kinetics during exercise. Medicine and Science in Sports and Exercise, 18(1), 101-106. PubMed doi:10.1249/00005768-198602000$\underline{00017}$

Shohet, K.L., \& Landrum, R.E. (2001). Caffeine consumption questionnaire: a standardized measure for caffeine consumption in undergraduate students. Psychological Reports 89(3), 521-526. PubMed doi:10.2466/pr0.2001.89.3.521

Tarnopolsky, M., \& Cupido, C. (2000). Caffeine potentiates low frequency skeletal muscle force in habitual and nonhabitual caffeine consumers. J Appl Physiol (1985), 89(5), 1719-1724.

West, J.B. (2012). Respiratory physiology: the essentials (9th ed.). Philadelphia: Lippincott Williams \& Wilkins.

Westerterp-Plantenga, M., Diepvens, K., Joosen, A. M., Bérubé-Parent, S., \& Tremblay, A. (2006). Metabolic effects of spices, teas, and caffeine. Physiol Behav., 30;89(1), 85-91.

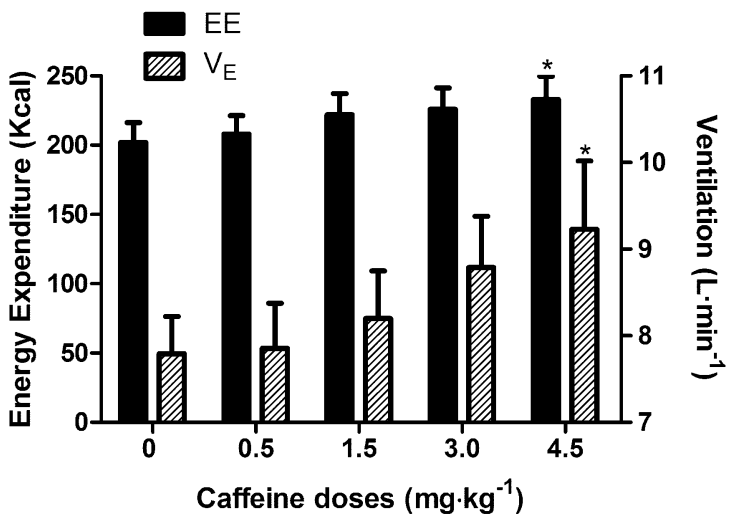

Figure 1 - Energy expenditure and ventilation during $3 \mathrm{hr}$ postexercise with different caffeine ingestion doses. Data are mean $\pm \mathrm{SD}$. *Different from $0 \mathrm{mg} \cdot \mathrm{kg}^{-1}$, control trial. 
A

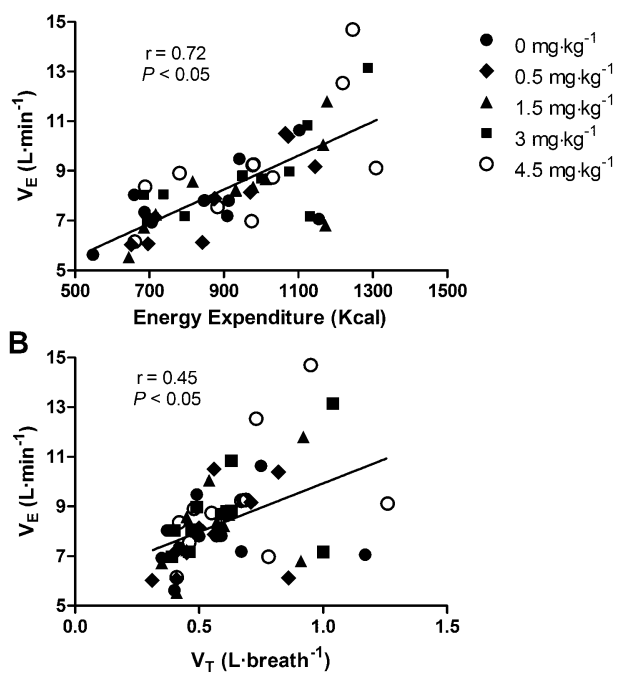

Figure 2 - A) Relationship between ventilation (VE) and energy expenditure during $3 \mathrm{hr}$ postexercise. B) Relationship between ventilation (VE) and tidal volume (VT) during $3 \mathrm{hr}$ postexercise. Pearson correlation $(r)$ from 12 subjects in five trials.

Table 1 Plasma Caffeine Levels $\left(\mathrm{ng} \cdot \mathrm{ml}^{-1}\right)$ During the $3 \mathrm{Hr}$ Postexercise Period

\begin{tabular}{llllll}
\hline & $0 \mathrm{mg} \cdot \mathrm{kg}^{-1}$ & $0.5 \mathrm{mg} \cdot \mathrm{kg}^{-1}$ & $1.5 \mathrm{mg} \cdot \mathrm{kg}^{-1}$ & $3.0 \mathrm{mg} \cdot \mathrm{kg}^{-1}$ & $4.5 \mathrm{mg} \cdot \mathrm{kg}^{-1}$ \\
\hline $1 \mathrm{hr}$ postexercise & $0.13 \pm 0.19$ & $0.78 \pm 0.51^{*}$ & $2.18 \pm 0.90^{*}$ & $3.82 \pm 1.85^{*}$ & $6.32 \pm 2.47^{*}$ \\
$2 \mathrm{hr}$ postexercise & $0.10 \pm 0.13$ & $0.65 \pm 0.32^{*}$ & $2.20 \pm 0.91^{*}$ & $3.54 \pm 1.23^{*}$ & $6.23 \pm 2.78^{*}$ \\
$3 \mathrm{hr}$ postexercise & $0.10 \pm 0.15$ & $0.60 \pm 0.33^{*}$ & $2.06 \pm 0.88^{*}$ & $3.82 \pm 1.34^{*}$ & $6.24 \pm 2.60^{*}$ \\
\hline
\end{tabular}

Note. Values are Mean $\pm S D$

*Different from all previous doses $(p<.05)$.

Table 2 Substrate Oxidation, Tidal Volume $\left(\mathrm{V}_{\mathrm{T}}\right)$ and Respiratory Frequency $\left(\mathrm{R}_{\mathrm{F}}\right)$ During the 3-Hr Postexercise Period

\begin{tabular}{lcccc}
\hline & Fat Oxidation (\%) & CHO Oxidation (\%) & $\mathrm{V}_{\mathrm{T}}\left(\mathrm{L} \cdot \mathrm{br}^{-1}\right)$ & $\mathrm{R}_{\mathrm{F}}\left(\mathrm{br} \cdot \mathrm{min}^{-1}\right)$ \\
\hline $0 \mathrm{mg} \cdot \mathrm{kg}^{-1}$ & $78.7 \pm 0.15$ & $21.3 \pm 0.15$ & $0.56 \pm 0.20$ & $15.5 \pm 4.7$ \\
$0.5 \mathrm{mg} \cdot \mathrm{kg}^{-1}$ & $73.5 \pm 0.17$ & $26.3 \pm 0.17$ & $0.57 \pm 0.26$ & $15.4 \pm 4.3$ \\
$1.5 \mathrm{mg} \cdot \mathrm{kg}^{-1}$ & $68.8 \pm 0.13$ & $31.2 \pm 0.13$ & $0.58 \pm 0.21$ & $15.1 \pm 3.7$ \\
$3.0 \mathrm{mg} \cdot \mathrm{kg}^{-1}$ & $70.6 \pm 0.20$ & $29.4 \pm 0.20$ & $0.61 \pm 0.25$ & $15.5 \pm 3.9$ \\
$4.5 \mathrm{mg} \cdot \mathrm{kg}^{-1}$ & $72.4 \pm 0.24$ & $27.6 \pm 0.24$ & $0.67 \pm 0.29^{*}$ & $15.2 \pm 3.4$ \\
\hline
\end{tabular}

Note. Values are mean $\pm S D$.

*Different from $0 \mathrm{mg} \cdot \mathrm{kg}^{-1}(p<.05)$. 
Table 3 Heart Rate, Blood Pressure and Blood_Concentration of Glucose, Lactate and Free Fatty Acids During the 3-Hr Postexercise Period

\begin{tabular}{lccccc}
\hline & $\mathrm{HR}\left(\right.$ beats $\left.\cdot \mathrm{min}^{-1}\right)$ & $\mathrm{MAP}(\mathrm{mmHg})$ & {$[\mathrm{Glu}]_{\text {serum }}\left(\mathrm{mmol} \cdot \mathrm{L}^{-1}\right)$} & {$[\mathrm{Lac}]_{\text {serum }}\left(\mathrm{mmol} \cdot \mathrm{L}^{-1}\right)$} & $\mathrm{FFA}\left(\mathrm{mmol} \cdot \mathrm{L}^{-1}\right)$ \\
\hline $0 \mathrm{mg} \cdot \mathrm{kg}^{-1}$ & $68 \pm 11$ & $84.1 \pm 1.9$ & $4.9 \pm 0.4$ & $1.2 \pm 0.3$ & $0.38 \pm 0.11$ \\
$0.5 \mathrm{mg} \cdot \mathrm{kg}^{-1}$ & $68 \pm 12$ & $83.6 \pm 1.7$ & $4.9 \pm 0.6$ & $1.2 \pm 0.2$ & $0.43 \pm 0.16$ \\
$1.5 \mathrm{mg} \cdot \mathrm{kg}^{-1}$ & $69 \pm 11$ & $83.5 \pm 2.0$ & $4.9 \pm 0.5$ & $1.3 \pm 0.3$ & $0.37 \pm 0.15$ \\
$3.0 \mathrm{mg} \cdot \mathrm{kg}^{-1}$ & $71 \pm 12$ & $86.3 \pm 2.0$ & $5.0 \pm 0.4$ & $1.4 \pm 0.2$ & $0.44 \pm 0.20$ \\
$4.5 \mathrm{mg} \cdot \mathrm{kg}^{-1}$ & $71 \pm 13$ & $86.0 \pm 2.0$ & $5.1 \pm 0.4$ & $1.3 \pm 0.3$ & $0.52 \pm 0.18$ \\
\hline
\end{tabular}

Note. Values are mean $\pm S D . \mathrm{HR}=$ heart rate, $\mathrm{MAP}=$ mean arterial pressure, $[\mathrm{Glu}]_{\text {serum }}=$ serum glucose concentration, $[\mathrm{Lac}]_{\text {serum }}=$ serum lactate concentration, FFA = blood free-fatty acid concentration. 
Page 10 of 10 